\title{
HUMAN MICROSPORIDIOSES AND AIDS: RECENT ADVANCES
}

\author{
I. DESPORTES-LIVAGE*
}

\section{Summary :}

Microsporidia, unicellular parasites frequent in animals, were rarely reported in humans before the advent of AIDS. This immunodeficiency syndrome induces the emergence or resurgence of opportunistic infections such as microsporidioses. Since 1985, five species of microsporidia have been found in HIV-infected patients. One of these species was already known in animals whereas all others are new. An increasing number of cases of microsporidioses is detected due to the improvement of methods of diagnosis. According to a study conducted in USA, intestinal microsporidia appear to be the first cause of diarrhea in patients with AIDS. These parasites are intensively investigated as shown by the increasing number of studies published since 1993. Most data concern the diagnosis, pathology, therapy and epidemiology of human microsporidioses as well as the characterization of their agents. Experimental studies aiming to define the immune context of these infections are also reported.

KEY WORDS : microsporidia, microsporidiosis, diagnosis, pathology, therapy, SIDA.

\section{INTRODUCTION}

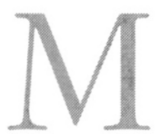

icrosporidia are unicellular parasites which infect a wide range of invertebrates including protozoa such as ciliates (Foissner \& Foissner, 1995). Also known in fish, birds and mammals (Canning \& Lom, 1986), they were rarely reported in humans before the advent of AIDS. Since 1985, four new species of microsporidia have been found in AIDS patients (Table I) and these parasites are gaining increasing attention as opportunistic pathogens responsible for significant morbidity. Most recent data, concerning human microsporidioses and their agents, are herein reported.

\section{GENERAL CHARACTERS OF MICROSPORIDIA}

$\checkmark$ hese protists are considered to be ancient eukaryotes. They have the nuclear organization of eukaryotes but they lack mitochondria, per-

* INSERM U313, CHU Pitié-Salpêtrière, 91, boulevard de l'Hôpital, 75013 Paris, France.

Tél. : 45.83.46.84 - Fax : 45.83.88.56.
Résumé : MICROSPORIDIOSES HUMAINES ET SIDA

Les microsporidies, parasites unicellulaires fréquents chez les animaux, étaient peu connues chez l'homme jusqu'à l'apparition du SIDA. Ce syndrome entraîne la résurgence ou l'émergence d'infections opportunistes parmi lesquelles figurent les microsporidioses. Cinq espèces de microsporidies dont quatre nouvelles ont été trouvées chez les patients atteints de SIDA et, avec l'amélioration des méthodes de diagnostic, le nombre des cas rapportés de microsporidioses ne cesse d'augmenter. Les atteintes digestives sont les plus fréquentes et, selon une enquête récemment effectuée aux États-Unis, les microsporidies intestinales seraient la première cause de diarrhées chez les patients atteints de SIDA. Ces parasites font l'objet d'un effort d'investigation intense comme le montre la quantité d'études publiées depuis 1994. Les informations ici rapportées sont relatives au diagnostic, aux aspects cliniques, thérapeutiques et épidémiologiques des microsporidioses ainsi qu'à la caractérisation de leurs agents. L'approche expérimentale visant à définir le contexte immunitaire de ces infections est également évoquée.

MOTS CLÉS : microsporidies, diagnostic, pathologie, thérapie, SIDA.

\section{Microsporidia}

Enterocytozoon bieneusi

(= Septata) intestinalis

Encephalitozoon bellem

Encephalitozoon cuniculi

Trachipleistophora bominis

Nosema connori

Nosema ocularum

Vittaforma corneae

$(=$ Nosema corneum $)$
Clinical symptoms
Abdominal cramping, nausea, weight loss, malabsorption, zinc deficiency, chronic diar- rhoea, cholecystitis, cholan- gitis, rhinosinusitis

Table I. - Microsporidian species parasite of man and their clinical manifestations according to the literature cited in text. $N$. ocularum Cali et al., 1991 and V. corneae Silveira \& Canning, 1995 have been only found in HIV-negative patients. The unique case of infection by N. connori Sprague 1974, has been reported in an athymic infant. $E$. cuniculi is also parasitic in animals (carnivora, lagomorphs, rodents). 
oxysomes, Golgi membranes, and their ribosomal RNA sequence is similar to that of prokaryotes (Vossbrinck et al., 1987). Their development occurs within cells of their hosts. It consists of a division phase followed by a spore producing phase. The only extracellular stages are mature spores which are released in the extracellular medium after the host cell death. Microsporidian spores possess a typical polar tube of which extrusion ensures the inoculation of the infecting sporoplasm into a host cell (Fig. 1).

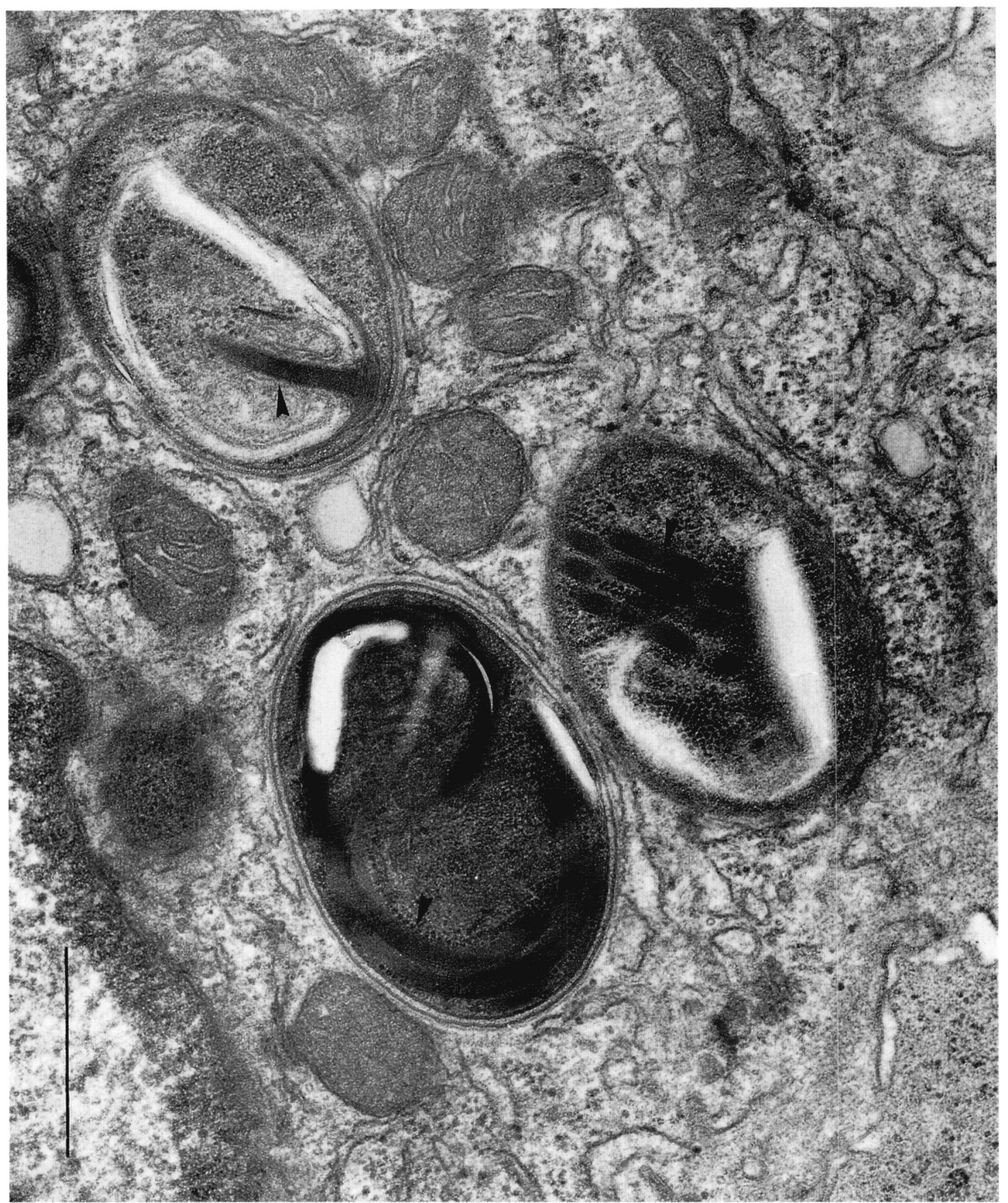

Fig. 1. - Transmission electron micrograph showing three spores of Enterocytozoon bieneusi at different stages of maturation in the cytoplasm of an enterocyte. Sections of the polar tube (arrowheads) are seen in the sporoplasm. These spores measure approximately $1.5 \times 0.8$ $\mu \mathrm{m}$. Scale bar $=0.5 \mu \mathrm{m}$ 


\section{AIDS RELATED MICROSPORIDIOSES}

linical manifestations of microsporidioses depend on the site on the infection. Enterocytozoon bieneusi, (Desportes et al., 1985), develops in the enterocytes of the small intestine. The species causes chronic diarrhea, abdominal cramping and nausea; it is also responsible for the malabsorption and the severe weight loss reported in AIDS patients, and appears to be involved in zinc deficiency as shown by the low levels measured in patients (Asmuth et al., 1994). This microsporidian could thus contribute to the progression to AIDS since deficiency in zinc is known to be related with progression to this syndrome (Graham et al., 1990 cited in Asmuth et al., 1994). The parasite has also been found in HIV infected patients without chronic diarrhea (Rabeneck et al., 1995). Although small intestine is the primay site of infection, Ent. bieneusi can also spread to the biliary ducts and nasopharyngeal epithelium, causing thereby some cases of cholangitis and rhinosinusitis (Weber et al., 1994). Encephalitozoon (= Septata) intestinalis is the second species known to cause diarrhea in AIDS patients (Cali et al., 1993; Hartskeerl et al., 1995). Encephalitozoon bellem has been isolated from ocular biopsies of patients with keratoconjonctivitis (Didier et al., 1991). Whereas Ent. Bieneusi appears to be restricted to epithelia, all species of the genus Encephalitozoon develop in a variety of cells including macrophages thus causing disseminated infections. Encephalitozoon intestinalis, Enc. bellem and Enc. cuniculi, a species already known to infect mammals, can cause rhinosinusitis, bronchiolitis, nephritis, ureteritis, hepatitis as well as peritonitis (Cali et al., 1993; Weber et al., 1994; Gunnarsson et al., 1995; Sobottka et al., 1995; Didier et al., 1996). Three cases of myositis were imputed to Pleistophora sp. (Ledford et al., 1985; Chupp et al., 1992; Hollister et al., 1995). Peculiarities observed in the sporogony of this parasite have lead to the creation of the genus Trachipleistophora with the species T. hominis (Hollister et al., 1995). Of all these species, Ent. bieneusi is the most frequent in AIDS patients. It is reported in 14 to $40 \%$ of HIVinfected patients with weight loss and chronic diarrhea (Asmuth et al., 1994; Weber et al., 1994). A recent evaluation of the prevalence of enteric pathogens in HIVinfected patients has shown that microsporidia are the major cause of diarrhea and other gastrointestinal manifestations (Kotler, 1995).

The interest of biologists and clinicians is mainly focused on the diagnosis and treatment of human microsporidioses. Most information concerning the characterization of these pathogens and their identification is provided by the study of in vitro models of microsporidial infections.

\section{TAXONOMICAL DATA}

he comparison of isolates of Encephalitozoon (= septata) intestinalis obtained from cultures on RK13 cell line (Van Gool et al., 1994) with those of Encephalitozoon cuniculi and Enc. bellem was performed by SDS-PAGE, western blotting and DNA analysis (Hartskeerl et al., 1995). Due to the homology (90 \%) found between gene sequences encoding for small subunits of ribosomal RNA, the species previously described under the generic name of Septata has been reclassified in the genus Encephalitozoon.

Genomic analyses have also shown that the microsporidian isolated from the urine and sputum of an AIDS patient corresponded to Encephalitozoon cuniculi, a species already known to infect carnivora, rodents or lagomorphs (De Groote et al., 1995). Similar results were obtained by Hollister. Interestingly the human isolate differed from canine and murine isolates (Hollister et al., 1995). A rabbit isolate has been also recently characterized (Didier et al., 1995).

\section{DETECTION}

\section{T}

he identification of intracellular stages of microsporidia requires histological studies of samples obtained by invasive procedures. Therefore, the detection of the spores released in excreta such as faeces, urine, bile, duodenal, bronchial or nasal fluids appears to be the most practical method of diagnosis. However it is hampered by the small-size of microsporidian spores. Actually, the uneasy diagnosis of microsporidia has been a cause of underestimation of the number of infected patients. Electron microscopy remains the best method for the specific identification of developmental stages and also for confirming the diagnosis performed with other techniques such as the staining by the fluorochrome Uvitex 2B (Van Gool et al., 1993) and the trichrome of Weber et al. (1992) modified by Kokoskin et al. (1994) which are extensively used for the identification of microsporidia in stools, urine and any other sample (De Girolami et al., 1995). New specific diagnostic tools have been proposed using immunological characterization or the PCR amplification of genes coding for conserved ribosomal RNA subunits.

\section{IMMUNODIAGNOSIS}

The production of specific antibodies directed against microporidian species as well as the detection of antibodies in patients' sera require large quantities of purified antigens. In vitro cultures of Encephalitozoon 
bellem and Enc. cuniculi provide millions of spores which are released in the supernatants. This material has been used for immunological identification and characterization (Aldras et al., 1994; Didier et al., 1991, 1995; Hollister et al., 1995; Schwartz et al., 1993; Visvesvara et al., 1995). Fluorescent antibody staining enabled the distinction between the two morphologically similar species Enc. bellem and Enc. cuniculi (Schwartz et al., 1993). In the absence of experimental models of Ent. bieneusi, other microsporidia have been tested for their serologic cross-reactivity with this species. Both Ent. bieneusi and Enc. intestinalis were thus aspecifically detected by indirect immunofluorescent antibody tests using murine polyclonal antisera raised in BALB/C mice immunized with spores of Enc. hellem or Enc. cuniculi (Aldras et al., 1994; Zierdt et al., 1993). A western blot technique using Glugea atherinae, a microsporidian parasitic in fish, has shown the cross-reactivity of sera from patients with microsporidiosis to Glugea antigens (Ombrouck et al., 1995). Since 1994, in vitro cultures of Enc. intestinalis permits the development of diagnostic procedures (Doultree et al., 1995; Hartskeerl et al., 1995). Polyclonal antibodies selectively directed against this species have been raised in rabbits (Aldras et al., 1994; Visvesvara et al., 1995) and mice (Hartskeerl et al., 1995). Ombrouck has recently proposed a method combining the non specific labeling of microsporidian spores by the fluorochrome Uvitex $2 \mathrm{~B}$ and an indirect immunofluorescent assay using a polyclonal antibody specifically directed against Enc. intestinalis (Ombrouck et al., 1996). Additionally this method enables the distinction between spores of this species and those of Enterocytozoon bieneusi which are only stained by fluorochome.

\section{PCR DETECTION}

The genomic amplification by the polymerase chain reaction for the detection and characterization of microsporidial infections in humans has been first investigated in the Netherlands and in the USA (Shuitema et al., 1993; Weiss et al., 1993; Zhu et al., 1994). Primers are selected in the conserved DNA sequence coding for the small subunit ribosomal RNA which contains species-specific sequences and has a characteristic small size. Using these primers, (SSU)rRNA gene fragments of Ent. bieneusi were detected in biopsies after amplication by the PCR method. Fedorko et al. (1995) have proposed a PCR assay for the detection of microsporidia in stool specimens. Presently, the species identification of Ent. bieneusi and Enc. intestinalis in stool samples can be performed within some hours due to a recent improvement of the PCR method (Ombrouck et al., 1996).

\section{HOST IMMUNITY AND MICROSPORIDIAL INFECTIONS}

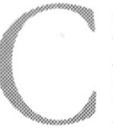

linical manifestations of microsporidioses as those of other opportunistic infections correlate with the intensity of infection and the decrease in the number of CD4t cells (CD4+ cell counts $<50$ per $\mathrm{mm}^{3}$ ) (Kotler, 1995). Animals models are helpful for understanding human infections and studying the relationships between microsporidia and the host immune system. A model of human encephalitozoonosis (Enc. cuniculi) has been obtained using SCID mice (Hermanek et al., 1993; Koudela et al., 1993). Experimental infections by Enc. cuniculi, Enc. hellem and Vittaforma corneae (= Nosema corneum) were also obtained by Didier et al. (1994) in different murine strains and monkeys. All these microsporidia cause asymptomatic and chronic infection in immunologically competent animals whereas immunocompromised ones die more or less rapidly according to the infecting species. Lethality was observed in generalized infections caused by the dissemination of the parasites by the macrophages. Experimental infections of $\mathrm{BALB} / \mathrm{c}$ mice have shown that the destruction of Enc. cuniculi by macrophages occurred in the presence of factors released by T-lymphocytes (Schmidt \& Shadduck, 1984 cited in Didier et al., 1994, 1995). In vitro studies have demonstrated that murine macrophages could kill Ent. cuniculi when they were treated with IFN-gamma in combination with lipopolysaccharide; a microbiostatic acitivity was obtained when macrophages were treated with IFN-gamma only (Didier \& Shadduck, 1994). According to Didier (1995), microbicidal or microbiostatic activities of activated macrophages occur through the nitric oxyde-dependent mechanism also involved in the killing of Leishmania major and other pathogens (Vouldoukis et al., manuscript in press). These in vitro data suggest that the lack of activating factors such as IFN-gamma due to TH1cell depletion (Del Prete \& Romagini, 1994) is involved in the spreading of Encephalitozoonosis in athymic mice.

\section{TREATMENT}

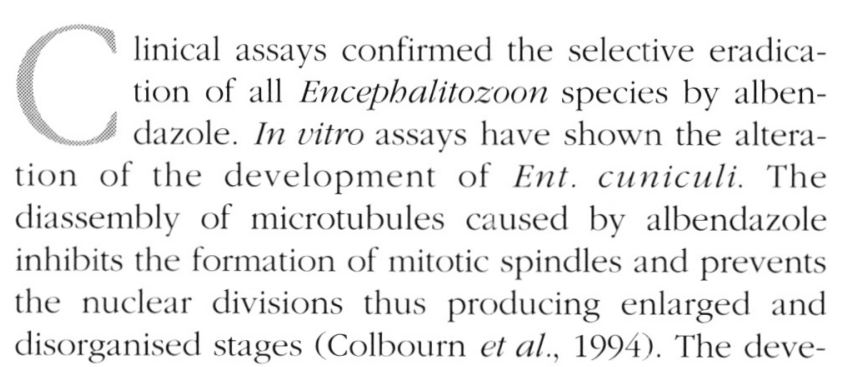


lopment of this species is also inhibited by fumagillin, 5-fluorouracil and sparfloxacin (Beauvais et al., 1994). Patients infected with Ent. intestinalis are successfully treated with albendazole as shown by the improvement in symptoms within days of start of therapy and the clearance of spores of the parasite in stools (Sobottka et al., 1995). It is noteworthy that spores of the parasite are still detected in the urine of some treated patients after the improvement of clinical symptoms. The persistence of infected sites could explain the parasitic relapses frequently observed in patients with severe immunodeficiency despite low-dose maintenance therapy with albendazole (Molina et al., 1995). Fumagillin has been used with success in the treatment of keratoconjunctivitis caused by Ent. hellem (Diesenhouse et al., 1993). Up to this date no therapy has proven to be effective against $E$. bieneusi.

\section{CONCLUSION}

T he increasing number of studies on human microsporidioses have contributed to the better characterization of their agents. They have also improved the diagnosis and the treatment of encephalitozoonoses. However specific treatments of Enterocytozoon bieneusi are not yet available. In addition the in vitro model of Ent. bieneusi is still lacking. No doubt that the obtention of long term culture of this species will facilitate the development of specific immunological tests and facilitate pharmacological studies. The method of isolation of microsporidian spores by flow cytometry developed by Challier et al. in 1994 can provide samples of spores of Ent. bieneusi. This material is presently selected in our laboratory for the production of antibodies and the infection of cell lines.

The epidemiology of human microsporidioses is under investigation. Spores of Ent. bieneusi have been found in stools of an immunocompetent traveller returning from tropical areas and without HIV infection (Sandfort et al., 1993). Similarly a case of infection by this microsporidia has been reported in a turkish child living in Germany on her return from a vacation trip in Turkey (Sobottka et al., 1995). These patients presented diarrhoea which resolved without treatment. Theses observations suggest that Ent. bieneusi cause intestinal infections which are spontaneously resolutive in immunocompetent people. The presence of Ent. bieneusi in an HIV-negative patient who was treated with cyclosporin after transplant therapy confirms the dramatic involvement of the immunodeficiency in the development and pathogenesis of microsporidioses (Monneret et al., 1995). It must be pointed out that some cases of microsporiodiosis observed in immunocompetent patients are limited to immunoprivileged sites as shown by corneal stroma infections caused by Nosema ocularum (Cali et al., 1991) and Vittaforma corneae (Silveira \& Canning, 1995). These data confirm the opportunistic character of microsporidial infections.

\section{REFERENCES}

Aldras A.M., Orenstein J.M., Kotler D.P., Shadduck J.A. \& DiDIER E.S. Detection of microsporidia by indirect immunofluorescence antibody test using polyclonal and monoclonal antibodies. Journal of Clinical Microbiology, 1994 , 32, 608-612.

Asmuth D.M., De Girolami P.C., Federman M., Ezratty C.R., Pleskow D.K., Desai G. \& Wanke C.A. Clinical features of microsporidiosis in patients with AIDS. Clinical Infectious Diseases, 1994, 18, 819-825.

Beauvais B., Sarfati C., Challier S. \& Derouin F. In vitro model to assess effect of antimicrobial agents on Encephalitozoon cuniculi. Antimicrobial Agents and Chemotherapy, 1994, 38, 2440-2448.

Cali A., Kotler D. \& Orenstein J.M. Septata intestinalis n.g., n.sp., an intestinal microsporidian associated with chronic diarrhea and dissemination in AIDS patients. The Journal of Eukaryotic Microbiology, 1993, 40, 101-112.

Cali A., Meisler D.M., Lowder C.Y., Lembach R., Ayers L., TaKvorian P., Rutherford I., Longworth D.L., McMahon J. \& BRYAN R.T. Corneal microsporidioses: characterization and identification. The Journal of Protozoology, 1991, 38, 215217S.

Canning E.U. \& Lom J., 1986. The microsporidia of vertebrates, Academic Press, London \& New york.

Challier S., Brown S., Ombrouck C., Desportes-livage I., De Nay D. \& Gentilini M. Flow cytometry as a possible method of isolation of spores of the microsporidian Enterocytozoon bieneusi. The Journal of Eukaryotic Microbio$\log y, 1994,41,27 \mathrm{~S}$.

Chupp G.L., Alroy J., Adelman l.S., Breen J.C. \& Skolnik P.R. Myositis dure to Pleistophora (Microsporidia) in a patient with AIDS. Clinical Infectious Diseases, 1992, 16, 15-21.

Colbourn N.I., Hollister W.S., Curry A. \& Canning E.U. Activity of albendazole against Encephalitozoon cuniculi in vitro. European Journal of Protistology, 1994, 30, 211-220.

De Girolami P.C., Ezratty C.R., Desai G., Mc Cullough A., Asmuth D., Wanke C. \& Federman M. Diagnosis of intestinal microsporidia by examination of stool and duodenal aspirate with Weber's modified trichrome and Uvitex 2B stains. Journal of Clinical Microbiology, 1995, 33, 805-810.

De Groote M.A., Visvesvara G., Wilson M.L., Pienazek N.J., Slemenda S.B., da Silva A.J., Leitch G.L., Bryan R.T. \& REEvEs R. Polymerase chain reaction and culture confirmation of disseminated Encephalitozoon cuniculi in a patient with AIDS: successful therapy with albendazole. The Journal of Infectious Diseases, 1995, 171, 1375-1378.

Del Prete G. \& Romagnini S. The role of Th1 and Th2 subsets in human infectious diseases. Trends in Microbiology, 1994, 2, 4-6. 
Desportes I., Le Charpentier Y., Galian A., Bernard F., Cochand-Priollet B., Lavergne A., Ravisse P. \& ModiGLIANI R. Occurrence of a new microsporidian: Enterocytozoon bieneusi n.g., n.sp. in the enterocytes of a human patient with AIDS. The Journal of Protozoology, 1985, 32, 250-254.

DiDIER E.S. Reactive nitrogen intermediates implicated in the inhibition of Encephalitozoon cuniculi (phylum Microspora) replication in murine peritoneal macrophages. Parasite Immunology, 1995, 17, 405-412.

Didier E.S., Didier P.J., Friedberg D.N., Stenson S.M., OrenStein J.M., Yee R.W., Tio F.O., Davis R.M., Vossbrinck C., Millichamp N. \& SHADDuck J.A. Isolation and characterization of a new human microsporidian Encephalitozoon bellem, n. sp. from three AIDS patients with keratoconjunctivitis. The Journal of Infectious Diseases, 1991, 163, 617-621.

Didier E.S., Rohers L.B., Orenstein J.M., Baker M.D., VossBRINCK C.R., VAN GOOL T., HaRTSKeERL R., SOAVE R. \& Beaudet L.M. Characterization of Encephalitozoon (Septata) intestinalis isolates cultured from nasal mucosa and bronchoalveolar lavage fluids from two AIDS patients. Journal of Eukaryotic Microbiology, 1996, 43, 34-43.

Didier E.S. \& SHADDUCK J.A. IFN-gamma and LPS induce murine macrophages to kill Encephalitozoon cuniculi in vitro. Journal of Eukaryotic Microbiology, 1994, 41, 34S.

Didier E.S., Vossbrinck C.R., Baker M.D., Rogers L.B., BerTUCCI D.C. \& SHADDUCK J.A. Identification and characterization of three Encephalitozoon cuniculi strains. Parasitology, 1995, 11, 411-421.

Didier E.S., Warner P.W., Didier P.J., Aldras A.M., MilliChamp N.J., Murphey-Corb M., Bohm R. \& Shadduck J.A. Experimental microsporidiosis in immunocompetent and immunodeficient mice and monkeys. Folia Parasitologica, 1994, 41, 1-11.

Diesenhouse M.C., Wilson L.A., Corrent G.F., Visvesvara G.S., Grossniklaus H.E. \& Bryan R.T. Treatment of microsporidial keratoconjunctivitis with topical fumagillin. American Journal of Ophtalmology, 1993, 115, 293-298.

Dore G.J., Marriott D.J., Hing M.C., Harkness J.L. \& Field A.S Disseminated microsporidiosis due to Septata intestinalis in nine patients infected with the human immunodeficiency virus: response to therapy with albendazole. Clinical Infectious Diseases, 1995, 21, 70-76.

Doultree J.C., Maerz A.L., Ryan N.J., Baird R.W., Wright E., Crowe S.M. \& Marshall J.A. In vitro growth of the microsporidian Septata intestinalis from an AIDS patient with disseminated illness. Journal of Clinical Microbiology, 1995, 33, 463-470.

Fedorko D., Nelson N.A. \& CARTwRight C.P. Identification of microsporidia in stool specimens by using PCR and restriction endonucleases. Journal of Clinical Microbiology, 1995, 33, 1739-1741.

FoIsSNER I. \& FoISSNER W. Ciliatosporidium platyophryae n.g., n.sp. (Microspora incertae sedis), a parasite of Platyophrya terricola (Ciliophora, Colpodea). European Journal of Protistology, 1995, 31, 248-259.

Gunnarsson G., Hulburt D., De Girolami P.C., Federman M
\& WANKE C. Multiorgan microsporidiosis: report of five cases and review. Clinical Infectious Diseases, 1995, 21, $37-44$.

Hartskeerl R.A., Van Gool T., Schuitema A.R., Didier E.S. \& TERPSTRA W.J. Genetic and immunological characterization of the microsporidian Septata intestinalis Cali, Kotler and Orenstein, 1993: reclassification to Encephalitozoon intestinalis. Parasitology, 1995, 110, 277-285.

Hermanek J., Koudela B., Kucerova Z., Ditrich O. \& TravNICEK J. Prophylactic and therapeutic immune reconstitution of SCID mice infected with Encephalitozoon cuniculi. Folia Parasitologica, 1993, 40, 287-291.

Hollister W.S., Canning E.U., Colbourn N.I. \& Aarons E.J. Encephalitozoon cuniculi isolated from the urine of an AIDS patient, which differs from canine and murine isolates. The Journal of Eukaryotic Microbiology, 1995, 42, 367-372.

Hollister W.S., Canning E.U., Weidner E., Field A.S., Kench J. \& MARRIOTT D. J. Development and ultrastructure of Trachipleistophora hominis n.g., n.sp., after in vitro isolation from an AIDS patient and inoculation into athymic mice. Parasitology, 1995, in press.

Kokoskin E., Gyorkos T.W., Camus A., Cedilotte L., Purtill T. \& WARD B. Modified technique for efficient detection of microsporidia. Journal of Clinical Microbiology, 1994, 32, 1974-1975.

Koudela B., Vitovec J., Ditrich O. \& Travnicek J. The severe combined immunodeficient mouse for a model for Encephalitozoon cuniculi microsporidiosis. Folia Parasitologica, 1993, 40, 279-286.

KotLER D.P. Gastrointestinal manifestations of human immunodeficiency virus. Advances in Internal Medicine, 1995 , 40, 197-242.

Ledford D.K., Overman M.D., Gonzalo A., Cali A., Mester W. \& LOCKEY R.F. Microsporidiosis myositis in a patient with acquired immunodeficiency syndrome. Annals of Internal Medicine, 1985, 102, 628-630.

Molina J.M., Oksenhendler E., Beauvais B., Sarfati C., JaCCard A., Derouin F. \& Modal J. Disseminated microsporidiosis due to Septata intestinalis in patients with AIDS: clinical features and response to albendazole therapy. The Journal of Infectious Diseases, 1995, 171, 245-249.

Monneret G., Rabodonirina M., Cotte L., Desportes-Livage I., Paulus S., Bastien O., Troncy J., Lachaux A., Boibieux A., Roumanet-Dubois F., Piens MA. \& Mojon M. Détection de spores de microsporidies intestinales dans une population non infectée par le virus de l'immunodéficience humaine. Annales de Biologie clinique, 1995, 53, 563-564.

Ombrouck C., Romestand B., Correia da Costa J.M., Desportes-Livage I., Datry A., Coste F., Bouix G. \& GenTILINI M. Use of cross-reactive antigens of the microsporidian Glugea atherinae for the possible detection of Enterocytozoon bieneusi by western blot. American Journal of Tropical Medicine and Hygiene, 1995, 52, 8993 .

Ombrouck C., Desportes-livage I., Achbarrou A. \& GentiLINI M. Specific detection of the microsporidia Encephalitozoon intestinalis in AIDS patients. Comptes-Rendus de 
l'Académie des Sciences, Paris, Sciences de la Vie, 1996, 319, 39-43.

Ombrouck C., Cicéron L., Desportes-Livage I. Specific and Rapid Detection of Microsporidia in Stool Specimens from AIDS patients by PCR. Parasite, 1996, 3, 85-86.

Rabeneck L., Genta R.M., Gyorkey F., Clarridge J.E., GYORKEY P. \& FOOTE L.W. Observations in the pathological spectrum and clinical course of microsporidiosis in men infected with the human immunodeficiency virus: followup study. Clinical Infectious Diseases, 1995, 20, 1229-1235.

Sandfort J., Hannemann A., Gelderblom H., Stark K., Owen R.L. \& RuF B. Enterocytozoon bieneusi infection in an immunocompetent patient who had acute diarrhea and who was not infected with the human immunodeficiency virus. Clinical Infectious Diseases, 1993, 18, 514-516.

Schwartz D.A., Visvesvara G.S., Diesenhouse M. C., Weber R., Font R.L., Wilson L.A., Corent G., Rosberger D.F., Grossniklaus H., Hewan-Lowe K. \& Bryan R.T. Ocular pathology of microsporidiosis: role of immunofluorescent antibody for diagnosis of Encephalitozoon hellem in biopsies, smears, and intact globes from seven AIDS patients. American Journal of Ophtalmology, 1993, 115, 285-292.

Shuitema A.R.J., Hartskeerl R.A., Van Gool T., LaxminaRAYAN R. \& Terpstra W.J. Application of the polymerase chain reaction for the diagnosis of microsporidiosis. AIDS, 1993, 7 (suppl. 3), S57-61.

Silveira H. \& Canning E.U. Vittaforma comeae N. Comb. for the human microsporidium Nosema corneum Shadduck, Meccoli, Davis \& Font, 1990, based on its ultrastructure in the liver of experimentally infected athymic mice. The Journal of Eukaryotic Microbiology, 1995, 42, 158-165.

Sobottka I., Albrecht H., SchäFer H., Schottelius J., Visvesvara G.S., Laufs R. \& Schwartz D.A. Disseminated Encephalitozoon (Septata) intestinalis infection in a patient with AIDS: novel diagnostic approaches and autopsy-confirmed parasitological cure following treatment with albendazole. Journal of Clinical Microbiology, 1995, 33, 2948-2952.

Sobottka I., Albrecht H., Schottelius J., Schmetz C., BentFEld M., LAufs R. \& SCHWARTZ D.A. Self-limited traveller's diarrhoea due to a dual infection with Enterocytozoon bieneusi and Cryptosporidium parum in an immunocompetent HIV-negative Child. European Journal of Clinical Microbiology and Infectious Diseases, 1995, 14, 919-920.

Sprague V. Nosema connori n. sp., a microsporidian parasite of man. Transactions of the American Microscopical Society, 1974, 93, 400-403.

Van Gool T., Canning E.U. \& Gilis H. Septata intestinalis frequently isolated from stool of AIDS patients with a new cultivation method. Parasitology, 1994, 109, 281-289.

Van Gool T., Snijders F., Eeftinck-Schattenkerk J.K.M., van der Berg Weerman M.A., Bartelsman J.F.W., Bruins J.J.M., Canning E.U. \& Dankert J.A. Diagnosis of microsporidial infections in HIV-infected individuals with a new rapid fluorescence technique. Journal of Clinical Pathology, 1993, 46, 694-699.

Visvesvara G.S., Leitch G. J., Da Silva A.J., Croppo G.P., Moura H., Wallace S., Slemenda S.B., Schwartz D.A., Moss D., Bryan R.T. \& Pieniazk N.J. Polyclonal and mono- clonal antibody and PCR-amplified small-subunit rRNA identification of a microsporidian, Encephalitozoon hellem, isolated from an AIDS patient with disseminated infection. Journal of Clinical Microbiology, 1995, 32, 2760-2768.

Visvesvara G.S., Da Silva A.J., Croppo G.P., Pieniazek N.J., Leitch G.J., Fergusson D., De Moura H., Wallace S., Slemenda S.B., Tyrrell I., Moore D.F. \& Meador J. In vitro culture and serologic and molecular identification of Septata intestinalis isolated from urine of a patient with AIDS. Journal of Clinical Microbiology, 1995, 33, 930-936.

Vossbrinck C.R., Maddux J.V., Friedman S., Debrunner-VossBRINCK B.A. \& WoEse C.R. Ribosomal RNA sequence suggests microsporidia are extremely ancient eukaryotes. Nature, 1987, 326, 411-414.

Vouldoukis I., Mazier D., Debré P. \& Mossalay M.D. Nitric oxyde and human infectious disease. Research in Immunology, in press.

Weber R., Bryan R.T., Owen R.L., Wilcox C.M., Gorelkin L. \& Visvesvara G.S. Improved light-microscopical detection of microsporidia spores in stool and duodenal aspirates. New England Journal of Medicine and Hygiene, 1992, 326, 161-166.

Weber R., Bryan R.T., Schwartz D.A. \& Owen R.L. Human microsporidial infections. Clinical and Microbiological Review, 1994, 7, 426-461.

Weiss L.M., Zhu X., Keohane E., Cali A., Tanowitz H.B. \& WitTner M. Polymerase chain reaction identification of microsporidia using ribosomal RNA. AIDS, 1993,7 (suppl. 3), S62-63.

Zhu X., Wittner M., Tanowitz H.B., Cali A. \& Weiss L.M. Ribosomal RNA sequences of Enterocytozoon bieneusi, Septata intestinalis and Ameson michaelis : phylogenetic construction and structural correspondence. The Journal of Eukaryotic Microbiology, 1994, 41, 204-209.

Zierdt C.H., Gill V.J. \& ZierdT W.S. Detection of microsporidian spores in clinical samples by indirect fluorescentantibody assay using whole-cell antisera to Encephalitozoon cuniculi and Encephalitozoon hellem. Journal of Clinical Microbiology, 1993, 31, 3071-3074. 